\title{
Updated phylogenetic description of the Mycoplasma hominis cluster (Weisburg et al. 1989) based on 165 rDNA sequences
}

\author{
Bertil Pettersson, ${ }^{1}$ Joseph G. Tully, ${ }^{2}$ Göran Bölske ${ }^{3}$ \\ and Karl-Erik Johansson ${ }^{3}$
}

\footnotetext{
1 Department of Biotechnology, The Royal Institute of Technology, S-100 44 Stockholm, Sweden

2 Mycoplasma Section, Frederick Cancer Research and Development Center, National Institute of Allergy and Infectious Diseases, Frederick, MD 21702, USA

3 Department of Bacteriology, Nationa Veterinary Institute, PO Box 7073, S-750 07 Uppsala, Sweden
}

Author for correspondence: Bertil Pettersson. Tel: +468 79082 87. Fax: +468245452. e-mail: bertil@biochem.kth.se

\begin{abstract}
The fastidious nature of the mollicutes (mycoplasmas), their lack of a classic bacterial cell wall, and their very small genome, make phylogenetic placements of new species in this enlarging group of prokaryotes an important and valuable aid in their classification. In this report we have determined the phylogeny of the Mycoplasma hominis cluster of the hominis group. The 16S rDNA sequences from several previously described Mycoplasma species were determined and ten species were found to belong to the $M$. hominis cluster. With almost complete sequences available, the phylogenetic analysis revealed that the $\boldsymbol{M}$. hominis cluster currently comprises 19 species, forming a distinct clade as judged from branch lengths, bootstrap percentage values, nucleotide signature analysis, and structural elements in the 16S rRNA molecule. The 165 rRNA gene sequences of species in the $M$. hominis cluster were found to be $\geq 94 \%$ similar and the range within which similarities can be used in the classification of new species is discussed. Members of the $M$. hominis cluster all share a major biochemical property of $M$. hominis, in that they hydrolyse arginine and are incapable of fermenting glucose. This consistency in phenotypic pattern has not been found in any of the other phylogenetic clusters of the hominis group. Two species, the non-cultivable agent of Grey Lung disease in rodents (tentatively named ' Candidatus Mycoplasma ravipulmonis') and the avian species Mycoplasma gypis strain $B 1 / 1^{\top}$, were regarded as close relatives to the $M$. hominis cluster, but are clearly separated from the species of this cluster. Both species formed early branches of the $M$. hominis cluster and should be regarded as individual lines containing one species.
\end{abstract}

Keywords: 16S rRNA, Mollicutes, Mycoplasma hominis cluster, phylogeny

\section{INTRODUCTION}

Mycoplasmas, which is the commonly accepted epithet of the wall-less micro-organisms belonging to the class Mollicutes, constitute a distinct phylogenetic lineage within the Gram-positives, characterized by having a low $\mathrm{G}+\mathrm{C}$ content in their genomes, in the domain Bacteria (Woese et al., 1980). The taxonomic description of new species within this group of pro-

Abbreviations: ML, maximum likelihood; NJ, neighbour joining.

The GenBank accession numbers for the 16S rRNA gene sequences determined in this paper are given in Table 1. karyotes has been complicated by their small size, fastidious and generally similar growth requirements, and especially by great reliance on detailed and laborious serologic analyses for species distinctions (International Committee on Systematic Bacteriology Subcommittee on the taxonomy of Mollicutes, 1995). The highly conserved primary structure of the $16 \mathrm{~S}$ rRNA molecule has shown useful properties for bacterial cladogenesis (Woese, 1987; Olsen \& Woese, 1993). In 1989, a phylogenetic analysis based on $16 \mathrm{~S}$ rRNA sequences was reported for the mollicutes by Carl R. Woese and co-workers (Weisburg et al., 1989). Almost 50 species were sequenced and the phylogenetic analysis revealed five distinct groups of descent, 
namely, the anaeroplasma group, the asteroleplasma group, the hominis group, the pneumoniae group and the spiroplasma group. Furthermore, the different groups were subdivided into several subgroups (clusters). The hominis group, which is the major group within the mycoplasmas was found to harbour six clusters (Weisburg et al., 1989; Pettersson et al., 1996b). These clusters are the Mycoplasma hominis cluster, the Mycoplasma lipophilum cluster, the Mycoplasma neurolyticum cluster, the Mycoplasma pulmonis cluster, the Mycoplasma sualvi cluster (Weisburg et al., 1989) and the Mycoplasma synoviae cluster (Pettersson et al., 1996b).

Although Weisburg et al. (1989) placed five species within the $M$. hominis cluster, other species have been added since, including Mycoplasma gatae strain $\mathrm{CS}^{\mathrm{T}}$ (Brown et al., 1995), Mycoplasma alkalescens strain $\mathrm{D} 12^{\mathrm{T}}$, Mycoplasma canadense strain $275 \mathrm{C}^{\mathrm{T}}$ (Pettersson et al., 1996b) and Mycoplasma auris strain UIA ${ }^{\mathrm{T}}$ (Heldtander et al., 1998). By analysing cloned partial 16S rRNA gene sequences (about 900-930 nt in length), Rawadi et al. (1998) found that the species Mycoplasma buccale DC-1600 and Mycoplasma faucium DC- $333^{\mathrm{T}}$ showed close phylogenetic relationships to members of the $M$. hominis cluster. The knowledge of the evolutionary relationships among the mycoplasmas is nevertheless scarce, despite these attempts to maintain a molecular phylogeny of the mycoplasmas.

The present investigation is focused on the phylogeny of the M. hominis cluster. For this purpose, the $16 \mathrm{~S}$ rRNA gene sequences of ten mollicutes were determined: $M$. buccale strain $\mathrm{CH} 20247^{\mathrm{T}}$ and $M$. faucium strain DC333 ${ }^{\mathrm{T}}$ (Freundt et al., 1974). Both were originally isolated from oropharynx of humans and they were formerly described as different types (types 2 and 3, respectively) of Mycoplasma orale. Hill et al. (1993) described the primate mycoplasma, Mycoplasma indiense $3 \mathrm{~T}^{\mathrm{T}}$. Mycoplasma spumans $\mathrm{PG} 13^{\mathrm{T}}$ was first isolated from the vagina of a dog and described by Edward \& Fitzgerald (1951). The name Mycoplasma equirhinis was first proposed for the mollicute strain M432/72 ${ }^{\mathrm{T}}$ isolated from equine nasopharynx and characterized by Allam \& Lemcke (1975). M. equirhinis has also been isolated from the nasopharynx, tonsils and trachea of horses, but the pathogenic significance has not been determined (Ross, 1993). Another equine species isolated from the genital tract of a mare, Mycoplasma subdolum $\mathrm{TB}^{\mathrm{T}}$, was described by Lemcke \& Kirchhoff (1979) and it has not been shown to be pathogenic (Ross, 1993). Mycoplasma anseris strain $1219^{\mathrm{T}}$ was isolated from the phallus of a goose and first described by Bradbury et al. (1988). Mycoplasma cloacale strain $383^{\mathrm{T}}$ was designated to an avian species, which was isolated from turkey (Bradbury \& Forrest, 1984). Mycoplasma falconis strain $\mathrm{H} / \mathrm{T}^{\mathrm{T}}$ and Mycoplasma gypis strain $\mathrm{B} 1 / \mathrm{T}^{\mathrm{T}}$ were isolated from the trachea of birds of prey (saker falcon and griffon vulture, respectively) and classified into separate species by Poveda et al. (1994). These mycoplasmas were isolated from birds with signs of respiratory disease, but pathogenicity has not been proven. All of the above species have either not had their 16S rRNA genes sequenced or have had incomplete sequences reported. The sequence data obtained here and the previously deposited complete $16 \mathrm{~S}$ rRNA gene sequences provide for a more complete definition of the M. hominis cluster, as well as offering guidelines for the assignment of other new species to this cluster.

\section{METHODS}

Bacterial strains, growth conditions and preparation of genomic DNA. All strains sequenced in this study were obtained from the mycoplasma culture collections at the National Veterinary Institute in Uppsala, Sweden, and at the Mycoplasma Section of the National Institute of Allergy $\&$ Infectious Diseases in Frederick, MD, USA (Table 1). The mycoplasmas were grown in appropriate media as described previously (Bölske, 1988). The cells were washed three times in PBS and DNA was prepared by phenol chloroform extraction according to standard procedures.

Determination of 16S rDNA sequences. The 16S rRNA genes of the species investigated in this study were amplified by PCR from genomic DNA. Two primer sets were used for the amplification. One set covered the U1-U5 regions (Gray et al., 1984) of the 16S rRNA gene and the other set defined the segment between the U2 and U8 regions. One primer was biotinylated in each of the two sets to generate products suitable for solid-phase $16 \mathrm{~S}$ rDNA sequencing. Primer information, PCR conditions, immobilization of PCR products and protocols for DNA sequencing has been described previously (Hultman et al., 1989, 1991; Johansson et al., 1998; Pettersson et al., 1996a, b). All codes used to denote nucleotide information are according to the International Union of Biochemistry.

Phylogenetic analysis. The sequences were aligned manually by using the Genetic Data Environment software (GDE) (Smith, 1992). Gaps were removed and the final alignment used for phylogenetic analysis comprised 1307 nucleotide positions. Phylogenetic calculations were performed by using algorithms implemented in the phylogenetic program package PHYLIP (Felsenstein, 1993). Infiles in the format compatible with that of PHYLIP were generated by using an option implemented in GDE. The tree was derived by using the neighbour-joining (NJ) program (Saitou \& Nei, 1987) from a distance matrix corrected for multiple substitutions at single locations by the one-parameter model of Jukes \& Cantor (1969). The data set was resampled 1000 times and the bootstrap percentage values are given at the nodes of the tree in Fig. 1. An evolutionary tree was also calculated by using maximum-likelihood (ML) applying the F84 evolutionary model with empirical nucleotide frequencies and a transition/transversion ratio set to 2.0 (Felsenstein, 1993). The option for global rearrangement was invoked to find the best tree.

Nucleotide sequence accession numbers. The 16S rRNA gene sequences determined in this work have been deposited in GenBank. The accession numbers of the deposited sequences and those retrieved for phylogenetic analysis are listed in Table 1. 
Table 1. Species and strains investigated for their inclusion in the $M$. hominis cluster

The species and strains with the following accession numbers were used as references in the phylogenetic analysis: M. agalactiae PG2T ${ }^{\mathrm{T}}$ U44763; 'M. agassizii' PS6, U09786; M. bovirhinis PG43 ${ }^{\mathrm{T}}$, U44766; M. conjunctivae HRC581 ${ }^{\mathrm{T}}$, U44770; M. felis CO ${ }^{\mathrm{T}}$, U09787; M. fermentans PG18 ${ }^{\mathrm{T}}$, M24289; M. gallinaceum DD ${ }^{\mathrm{T}}$, L24104; M. hyorhinis BTS7 ${ }^{\mathrm{T}}$, M24658; M. iowae 695 ${ }^{\mathrm{T}}$, M24293; M. lipophilum $\mathrm{MaBy}^{\mathrm{T}}$, M24581; M. mobile $163 \mathrm{~K}^{\mathrm{T}}$, M24480; M. mycoides subsp. mycoides SC; PG1 ${ }^{\mathrm{T}}$, U26038; M. neurolyticum Type $\mathrm{A}^{\mathrm{T}}$, M23944; M. ovipneumoniae Y98 ${ }^{\mathrm{T}}$, U44771; M. pneumoniae $\mathrm{FH}^{\mathrm{T}}$, M29061; M. pulmonis PG34 ${ }^{\mathrm{T}}$, AF125582 - a more complete $16 \mathrm{~S}$ rRNA gene sequence from $M$. pulmonis $\mathrm{PG} 4^{\mathrm{T}}$ was determined and used in this work; M. sualvi Mayfield $\mathrm{B}^{\mathrm{T}}$, M23936; M. synoviae WVU $1853^{\mathrm{T}}$, L07757.

\begin{tabular}{|c|c|c|c|c|c|}
\hline Species & Strain & Main host & Glu/Arg & Accession no.* & Reference \\
\hline Mycoplasma alkalescens & $\mathrm{D} 12^{\mathrm{T}}$ & Bovine & $-/+$ & U44764 & Pettersson et al. (1996b) \\
\hline Mycoplasma anseris & $1219^{\mathrm{T}}$ & Avian & $-/+$ & AF125584 & This study \\
\hline Mycoplasma arginini & $\mathrm{G} 230^{\mathrm{T}}$ & Caprine/ovine & $-/+$ & AF125581, U15794 & This study; Brown et al. (1995) \\
\hline Mycoplasma arthritidis & $\mathrm{PG}^{\mathrm{T}}$ & Murine & $-/+$ & M24580 & Weisburg et al. (1989) \\
\hline Mycoplasma auris & $\mathrm{U}_{1} \mathrm{~A}^{\mathrm{T}}$ & Caprine & $-/+$ & U67944 & Heldtander et al. (1998) \\
\hline Mycoplasma buccale & $\mathrm{CH} 2 \mathrm{O} 247^{\mathrm{T}}$ & Human/primate & $-/+$ & AF125586 & This study \\
\hline Mycoplasma canadense & $275 \mathrm{C}^{\mathrm{T}}$ & Bovine & $-/+$ & U44769 & Pettersson et al. (1996b) \\
\hline Mycoplasma cloacale & $383^{\mathrm{T}}$ & Avian & $-/+$ & AF125592 & This study \\
\hline Mycoplasma equirhinis & $\mathrm{M} 432 / 72^{\mathrm{T}}$ & Equine & $-/+$ & AF 125585 & This study \\
\hline Mycoplasma falconis & $\mathrm{H} / \mathrm{T} 1^{\mathrm{T}}$ & Avian & $-/+$ & AF125591 & This study \\
\hline Mycoplasma faucium & DC $333^{\mathrm{T}}$ & Human/primate & $-/+$ & AF 125590 & This study \\
\hline Mycoplasma gateae & $\mathrm{CS}^{\mathrm{T}}$ & Feline & $-/+$ & U15796 & Brown et al. (1995) \\
\hline Mycoplasma hominis $†$ & $\mathrm{PG} 21^{\mathrm{T}}$ & Human & $-/+$ & AJ002265 & Mygind et al. (1998) \\
\hline Mycoplasma hyosynoviae & $\mathrm{S} 16^{\mathrm{T}}$ & Porcine & $-/+$ & U26730 & Blank et al. (1996) \\
\hline Mycoplasma indiense & $3 \mathrm{~T}^{\mathrm{T}}$ & Primate & $-/+$ & AF125593 & This study \\
\hline Mycoplasma orale & $\mathrm{CH} 19299^{\mathrm{T}}$ & Human/primate & $-/+$ & M24659 & Weisburg et al. (1989) \\
\hline Mycoplasma salivarium & $\mathrm{PG} 20^{\mathrm{T}}$ & Human & $-/+$ & AF125583; M24661 & $\begin{array}{l}\text { This study; Weisburg et al. } \\
\text { (1989) }\end{array}$ \\
\hline Mycoplasma spumans & PG13 ${ }^{\mathrm{T}}$ & Canine & $-/+$ & AF 125587 & This study \\
\hline Mycoplasma subdolum & $\mathrm{TB}^{\mathrm{T}}$ & Equine & $-/+$ & AF125588 & This study \\
\hline Mycoplasma gypis & $\mathrm{B} 1 / \mathrm{T} 1^{\mathrm{T}}$ & Avian & $-/+$ & AF125589 & This study \\
\hline $\begin{array}{l}\text { 'Candidatus Mycoplasma } \\
\text { ravipulmonis' }\end{array}$ & & Rodent & Not cultured & AF001173 & Neimark et al. (1998) \\
\hline
\end{tabular}

* Accession numbers in bold denote almost complete 16S rDNA sequences that were determined in this work.

$\dagger$ M. hominis PG $21^{\mathrm{T}}$ was resequenced in this work, but it was found to be identical to AJ002265 and was therefore not deposited.

\section{RESULTS AND DISCUSSION}

\section{Nucleotide sequences of the 16S rRNA gene}

Almost complete 16S rDNA sequences were generated for 13 type strains of Mycoplasma species (Table 1) by direct solid-phase 16S rDNA sequencing. Sequences were determined for ten species described previously, but for which 16S rRNA gene sequences have not been deposited or only a fraction of the gene has been reported. Four species (including Mycoplasma pulmonis $\mathrm{PG} 34^{\mathrm{T}}$ ) were selected for resequencing to solve ambiguous positions and to investigate the nucleotide information of certain positions in previously published $16 \mathrm{~S}$ rRNA gene sequences. Almost complete sequences were unambiguously determined and ranged between 1459 and 1469 nt in length. The use of direct solid-phase 16S rRNA gene sequencing results in simultaneous determination of nucleotide sequences from the 16S rRNA genes. This means that polymorphisms found in mycoplasmas having two rrn operons are due to nucleotide differences between the two 16S rRNA genes (Heldtander et al., 1998; Pettersson et al., 1994, 1996a, b, 1998). Polymorphisms were found in only some of the species sequenced in this work and with the following compositions. $M$. falconis $\mathrm{H} / \mathrm{T}^{\mathrm{T}}, \mathrm{A} / \mathrm{G}_{134}, \mathrm{C} / \mathrm{T}_{842}, \mathrm{~A} / \mathrm{G}_{843}$ and $\mathrm{A} / \mathrm{G}_{844}$; M. equirhinis $\mathrm{M} 432 / 72^{\mathrm{T}}, \mathrm{A} / \mathrm{C}_{152}$ and $\mathrm{C} / \mathrm{T}_{707} ;$ Mycoplasma arginini $\mathrm{G} 230^{\mathrm{T}}, \mathrm{C} / \mathrm{T}_{(208)}$ and $\mathrm{A} / \mathrm{G}_{396}$; and finally $M$. spumans $\mathrm{PG} 13^{\mathrm{T}}, \mathrm{A} / \mathrm{G}_{219}$ and $\mathrm{C} / \mathrm{T}_{1277}$. The numbers given as subscripts refer to the positions in the 16S rRNA molecule of Escherichia coli (Brosius et al., 1978). The position given within parentheses is lacking a corresponding nucleotide in E. coli. This polymorphism is found in the tetra-loop starting at position 208 (in E. coli). The homologous loop in $M$. arginini $\mathrm{G} 230^{\mathrm{T}}$ is three nucleotides longer than that in $E$. coli. Interestingly, the three consecutive heterogeneities in the positions 842-844 of the 16S rRNA gene of $M$. falconis $\mathrm{H} / \mathrm{T} 1^{\mathrm{T}}$ constitute a tri-loop in the V8-region of the 16S rRNA molecule (Gray et al., 1984). We have been characterizing polymorphisms in the 16S rRNA molecule of the genus Mycoplasma to a 


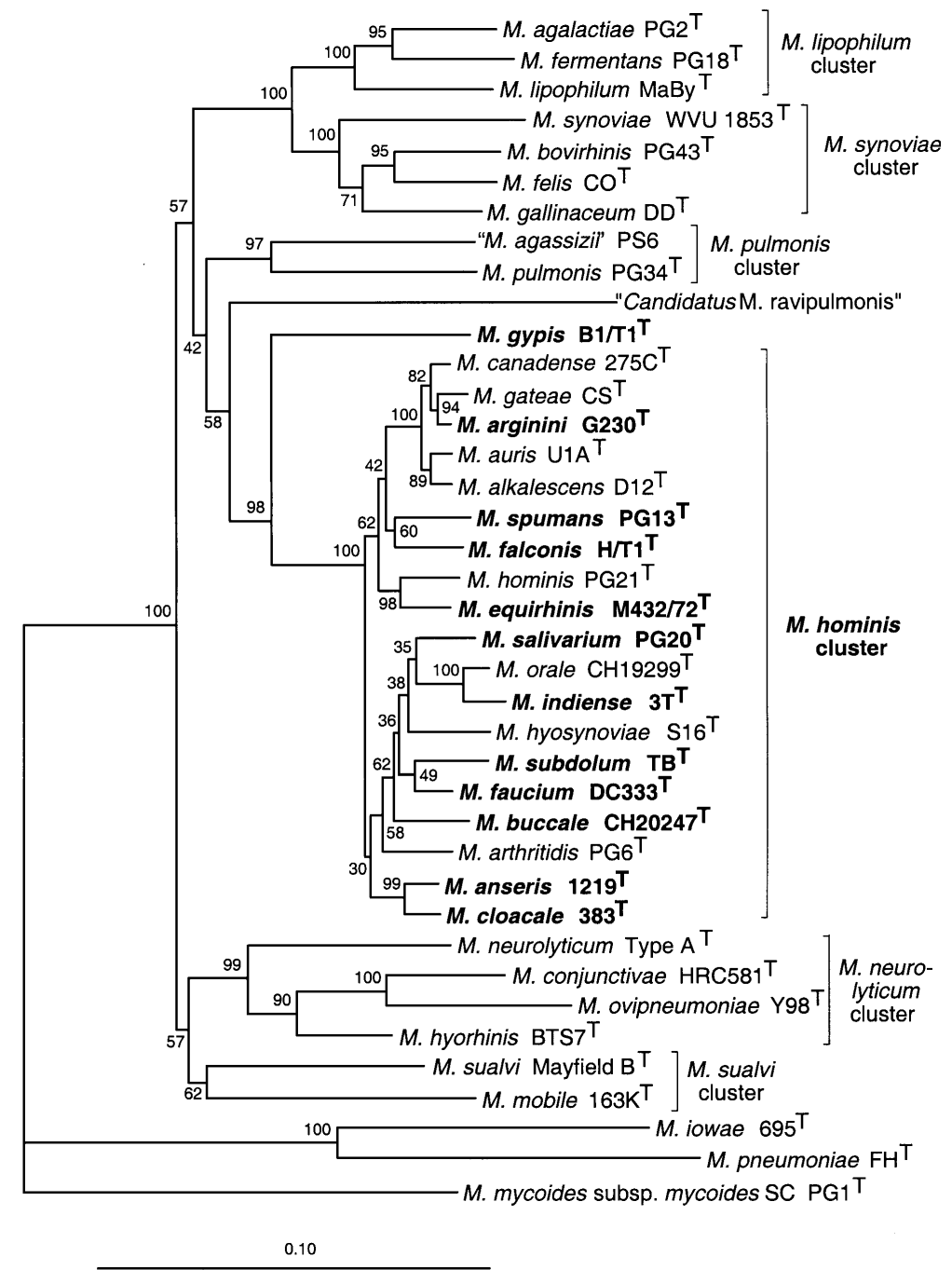

Fig. 1. Evolutionary distance tree showing the phylogeny of the hominis group with emphasis on the $M$. hominis cluster. $M$. mycoides subsp. mycoides SC PG $1^{\top}$ of the spiroplasma group served as the outgroup and $M$. pneumoniae and $M$. iowae, both belonging to the pneumoniae group of the mollicutes were included for comparison. Bootstrap percentage values obtained from 1000 resamplings of the data set are given at the nodes. Bold letters indicate that the actual species was sequenced in this work. The scale bar shows the equivalent distance to 0.1 substitutions per nucleotide position. considerable extent, but have never observed such a dense occurrence of heterogeneities. It should be pointed out that the nucleotide compositions of the individual $16 \mathrm{~S}$ rRNA genes were not determined, since the PCR products were not cloned prior to DNA sequencing.

\section{Phylogenetic considerations and placement of the M. hominis cluster}

It is convenient to use only one systematic framework with a consistent nomenclature (e.g. Weisburg et al., 1989) when describing evolutionary relationships of the mollicutes. The reason for this is to avoid confusion and to allow comparison and facilitated overview of the results obtained by different research groups. As detailed in the introduction, in a survey determining the phylogeny of the mycoplasmas and their walled relatives, Weisburg et al. (1989) compared 16S rRNA sequences to organize this group of organisms. The mollicutes were arranged into groups and the in- dividual groups were named after a representative genus or species in each group. To further delineate these phylogenetic entities, the groups were divided into clusters and named after a representative species contained in the actual cluster. The epithet of a cluster is created by using the binominal name of a representative species, which is phylogenetically positioned in that actual cluster (e.g. the M. hominis cluster). Preferably, the groups and clusters should be verified and defined by analysis of derived (apomorphic) homologous characters in the 16S rRNA molecule such as signature nucleotides and higher order structural attributes (Weisburg et al., 1989; Pettersson et al., 1996b). By using this procedure we believe that a highly flexible system will be achieved to which new species, clusters and groups can be added without the need for large rearrangements.

At present, we have determined the nucleotide sequences of the $16 \mathrm{~S}$ rRNA genes from more than 50 previously described species and strains belonging to the genus Mycoplasma, but for which 16S rDNA data 
have not been deposited into the databases. Currently, an alignment that comprises $>300$ mollicute sequences is maintained at our institute. The species used for detailed comparison in this study were selected as judged from a dendrogram inferred from all of the $16 \mathrm{~S}$ rRNA gene sequences of the taxa included in this alignment. Species to be placed in the M. hominis cluster and a selection of type strains belonging to the other clusters within the hominis group were extracted to study the phylogeny of the $M$. hominis cluster (Table 1). Mycoplasma pneumoniae strain $\mathrm{FH}^{\mathrm{T}}$ and Mycoplasma iowae strain $695^{\mathrm{T}}$, representing the pneumoniae group, were selected for comparison. The type species of the mollicutes, Mycoplasma mycoides subsp. mycoides SC strain PG1 ${ }^{\mathrm{T}}$, phylogenetically positioned in the spiroplasma group, was used as outgroup in the tree. The inter-species relationships are displayed in the NJ tree shown in Fig. 1 and its overall topology resembles the previously published dendrogram by Pettersson et al. (1996b). The tree showed almost identical overall topology to a tree computed by ML, but Mycoplasma mobile strain $163 \mathrm{~K}^{\mathrm{T}}$ and $M$. sualvi strain Mayfield $\mathrm{B}^{\mathrm{T}}$ did not group together in the cladogram derived by ML. In the ML tree, M. mobile $163 \mathrm{~K}^{\mathrm{T}}$ formed an early branch of the hominis group while $M$. sualvi Mayfield $\mathrm{B}^{\mathrm{T}}$ diverged early from the common ancestral branch of the $M$. neurolyticum cluster. The bootstrap value at the actual node in Fig. 1 indicated that the statistical support $(62 \%)$ for $M$. mobile $163 \mathrm{~K}^{\mathrm{T}}$ and $M$. sualvi Mayfield $\mathrm{B}^{\mathrm{T}}$ sharing a common ancestral node was moderate. As discussed previously these species are likely to be defined as constituting separate lines within the hominis group and not grouped together in a common cluster (Pettersson et al., 1996b). The conflicting phylogenetic results of these organisms when using distance matrix based or character based tree building will be discussed elsewhere.

\section{The phylogeny of the $M$. hominis cluster and definition of the $M$. alkalescens subcluster}

The $M$. hominis cluster formed a stable phylogenetic unit in both the NJ tree and the ML tree as judged from branch lengths and bootstrap percentage values. Moreover, unique nucleotide positions and structural elements (below) defined the M. hominis cluster. As judged from the tree in Fig. 1 and a non-corrected similarity matrix (not shown, can be obtained upon request) there are two taxa which are to be regarded as being more distantly related to the $M$. hominis cluster. These are the Grey Lung agent and M. gypis strain $\mathrm{B} 1 / \mathrm{T} 1^{\mathrm{T}}$. The former has so far not been cultivated and was therefore named 'Candidatus Mycoplasma ravipulmonis' for later inclusion in the genus $\mathrm{Myco-}$ plasma (Neimark et al., 1998). By comparing 16S rDNA sequences, Neimark et al. (1998) placed 'Candidatus M. ravipulmonis' between $M$. pulmonis strain PG $34^{\mathrm{T}}$ and the hominis cluster forming an early branch of the latter. This is in general agreement with our findings. In Fig. 1, 'Candidatus Mycoplasma ravipulmonis' was found to be positioned between the ancestral lineage shared by 'Mycoplasma agassizii' strain PS6 and M. pulmonis strain PG34 ${ }^{\mathrm{T}}$, and the line formed by M. gypis B1/T1 ${ }^{\mathrm{T}}$ in all trees (Fig. 1). Both 'Candidatus M. ravipulmonis' and $M$. gypis $\mathrm{B} 1 / \mathrm{T}^{\mathrm{T}}$ constituted early and distinct lines of the $M$. hominis cluster (Fig. 1). Despite the fact that the branching order in this locale of the tree was only partly supported by bootstrap values, this topology was found also when including more taxa and using different programs for tree construction. Furthermore, there are also signature nucleotides and structural motifs in the $16 \mathrm{~S}$ rRNA molecule that, to a certain extent, suggest a shared common ancestry between these species and the members of the M. hominis cluster (discussed below). However, the percentage values of $16 \mathrm{~S}$ rRNA gene sequence similarity indicated a marked distance between these two species and to the $M$. hominis cluster. Comparison of the similarity value of 'Candidatus M. ravipulmonis' with those of $M$. gypis $\mathrm{B} 1 / \mathrm{T}^{\mathrm{T}}$, the $M$. hominis cluster, and other clusters of the hominis group, showed a rather distant relationship $<87 \%$ to any member of the hominis group (not shown). Also the 16S rDNA sequence of M. gypis $\mathrm{B} 1 / \mathrm{T}^{\mathrm{T}}$ was found to be $\leqslant 92 \%$ similar to any of the species in the $M$. hominis cluster, while the range of similarity among species within the $M$. hominis cluster is $\geqslant 94 \%$. Interestingly, the branch leading to 'Candidatus M. ravipulmonis' is almost twice the length of that of the other taxa in the hominis group and almost five times the mean branch length found in the M. hominis cluster (Fig. 1). Similarly, the number of changed characters in $M$. gypis $\mathrm{B} 1 / \mathrm{T}^{\mathrm{T}}$ is almost three times that of any member of the $M$. hominis cluster. This observation indicates that these species originated much earlier than the members of the $M$. hominis cluster or that the two lines are characterized by having higher evolutionary rates of the $16 \mathrm{~S}$ rRNA gene. Another explanation would be the effect of phylogenetic noise adding to the creation of long-branch artifacts. This question can be answered when data from more closely related taxa have been obtained. By analysing the tree, it was concluded that the $M$. hominis cluster accommodates the 19 members marked with a vertical line in Fig. 1. Consequently, 'Candidatus M. ravipulmonis' and $M$. gypis $\mathrm{B} 1 / \mathrm{T}^{\mathrm{T}}$ are to be regarded as separate lines, each containing only one species.

Most of the internal nodes of the $M$. hominis cluster were found to be associated with rather weak bootstrap values (Fig. 1), which was also reflected by a slightly different internal branching order that was achieved when ML was applied on the data set. This observation indicates the difficulty in depicting subclusters of the $M$. hominis cluster and that attempts to reveal the internal branching order were not considered meaningful. Nevertheless, one subcluster, containing the species $M$. alkalescens $\mathrm{D} 12^{\mathrm{T}}, M$. arginini $\mathrm{G} 230^{\mathrm{T}}, M$. auris $\mathrm{U}^{\mathrm{T}} \mathrm{A}^{\mathrm{T}}, M$. canadense $275 \mathrm{C}^{\mathrm{T}}$ and $M$. gateae $\mathrm{CS}^{\mathrm{T}}$ 
was notable. Both NJ and ML gave congruent topologies by grouping these species together in a subclade within the $M$. hominis cluster. Moreover, these species showed strikingly high $16 \mathrm{~S}$ rDNA similarity values in the range of $98.0 \%$ to $99.4 \%$ and they will be referred to as the $M$. alkalescens subcluster. The level of sequence similarity between members of the $M$. alkalescens subcluster was found to be $\geqslant 1.6 \%$ above the value generally found among the other members of the $M$. hominis cluster.

\section{Nucleotide analysis of the 16S rRNA molecule of the M. hominis cluster}

All species of the $M$. hominis cluster were found to have a uridine residue in the position 912 in the $16 \mathrm{~S}$ rRNA molecule. This is a highly conserved attribute, which is almost entirely found among the members of the hominis group in the domain Bacteria (Weisburg et al., 1989). The branch of the M. hominis cluster was found to be supported by signature nucleotide positions, shown in bold faced letters in Table 2. A signature nucleotide in this context is a nucleotide residue explicitly found in a position within the sequence where the base present differs from that found in the majority of the other eubacteria. Perhaps the most pronounced attribute is found in the highly conserved region in the loop starting at the position 1090 (Van de Peer et al., 1996), where the M. hominis cluster (except $M$. falconis $\mathrm{H} / \mathrm{T}^{\mathrm{T}}$ ) can be recognized by an idiosyncratic cytidine residue in position 1091 . Thus, the M. hominis cluster exhibits the following oligonucleotide, GGUCAAG in this locale of the $16 \mathrm{~S}$ rRNA molecule. This feature is not found in the $16 \mathrm{~S}$ rRNA molecule of any other member of the class Mollicutes and also occurs rarely in the domain Bacteria. Five sequences that did not obey this rule were found in the genera Butyrivibrio and Bifidobacterium. Another signature for the $M$. hominis cluster was found to be $\mathrm{C}_{152}$, where almost all other eubacteria $(\geqslant 99.5 \%)$ have a purine (Maidak et al., 1999; Ribosomal Database Project, 1999). However, two exceptions were found, in that the deposited $16 \mathrm{~S}$ rRNA sequence of $M$. arthritidis, $\mathrm{PG}^{\mathrm{T}}$ had an adenosine and $M$. subdolum $\mathrm{TB}^{\mathrm{T}}$ had a uridine in the position 152 . The primary structure of the 16S rRNA molecule of $M$. subdolum $\mathrm{TB}^{\mathrm{T}}$ was determined in this work and the sequence was therefore rechecked and the results confirmed the presence of this uridine residue. Two other positions, namely $\mathrm{U}_{504}$ and $\mathrm{G}_{974}$, clearly distinguished the common branch of 'Candidatus M. ravipulmonis', M. gypis $\mathrm{B} 1 / \mathrm{T}^{\mathrm{T}}$ and the $M$. hominis cluster from other bacterial taxa. The uridine residue in position 504 and the guanosine residue in position 974 are not seen among other mollicute taxa and only sparsely found in other microorganisms of the domain Bacteria. The $\mathrm{U}_{504}$ is also found in the genus Wolbachia, which is phylogenetically positioned in the $\alpha$-subclass of the class Proteobacteria and the anaerobic halophiles of the Gram-positive phylum. It is, therefore, likely that these attributes were shared by the ancestor from which 'Candidatus M. ravipulmonis', $M$. gypis $\mathrm{B} 1 / \mathrm{T}^{\mathrm{T}}$ and the $M$. hominis cluster once evolved. These sequence features can thus be regarded as synapomorphic for this clade supporting the topology of the phylogram (Fig. 1). The positions $\mathrm{C}_{152}$ and $\mathrm{G}_{974}$ were also shared by the anaerobic mollicute, Asteroleplasma anaerobium $161^{\mathrm{T}}$.

The $M$. hominis cluster could also be defined by unique nucleotide positions in the $16 \mathrm{~S}$ rRNA molecule (Table 2 ). The characterization of unique nucleotide features was restricted to the hominis group and/or the class Mollicutes. Generally, a nucleotide residue at a certain position was said to be unique when present in the molecule of all strains within the $M$. hominis cluster, and with only a few exceptions among the strains of any other cluster or group. Some exceptions to this rule are listed in Table 2.M. gypis $\mathrm{B} 1 / \mathrm{T} 1^{\mathrm{T}}$ and 'Candidatus M. ravipulmonis' were treated separately in this analysis. The dominating residues that can be found in the corresponding positions in the other members of the hominis group and in other mollicute groups are shown in Table 2. As seen in this table, there are certain positions that suggest an inclusion or an exclusion of $M$. gypis $\mathrm{B} 1 / \mathrm{T} 1^{\mathrm{T}}$ and/or 'Candidatus M. ravipulmonis' from the $M$. hominis cluster. This finding supports the above discussion regarding 'Candidatus M. ravipulmonis' and M. gypis $\mathrm{B} 1 / \mathrm{T}^{\mathrm{T}}$ being closely related to the $M$. hominis cluster, but also not to be included in this phylogenetic unit. Interestingly, all positions shown in Table 2 also supported the branching order between 'Candidatus M. ravipulmonis', $M$. gypis $\mathrm{B} 1 / \mathrm{T}^{\mathrm{T}}$ and the $M$. hominis cluster as revealed in Fig. 1. This statement can easily be visualized, because the homologous residues found in the 16S rRNA molecule of the other members of the hominis group should be regarded as ancestral states of nucleotide characters (Table 2).

Moreover, two positions were found in the alignment that showed characteristic nucleotides $\left(\mathrm{A}_{447}\right.$ and $\left.\mathrm{C}_{490}\right)$ for the $M$. alkalescens subcluster, with only a few exceptions found in the hominis group and other phylogenetic groups of the Mollicutes. Thus the entity formed by the five species including $M$. alkalescens $\mathrm{D} 12^{\mathrm{T}}$ as obtained both by $\mathrm{NJ}$ and $\mathrm{ML}$, can be regarded as constituting a significant subclade within the $M$. hominis cluster of the hominis group.

\section{Structural motifs in the 16S rRNA molecule of the $M$. hominis cluster}

The members of the M. hominis cluster also possessed homologous higher-order structural features of the 16S rRNA molecule. All members of the M. hominis cluster showed a one base truncation in the helix starting at position 184 (E. coli numbering) compared to other members of the hominis group. When compared to E. coli, the helix in the 16S rRNA molecules of the mycoplasmas is extended by 6-7 bp in the actual region, making it impossible to give the exact positions 
Table 2. Unique and signature nucleotide positions in the $16 \mathrm{~S}$ rRNA molecule of the $M$. hominis cluster

The number of an actual position corresponds to that in the 16S rRNA molecule of E. coli (Brosius et al., 1978). Signatures are shown in bold, and lower-case letters denote occasionally found residues and R follows the ambiguity code according to The International Union of Biochemistry.

\begin{tabular}{|c|c|c|c|c|c|c|}
\hline \multirow{2}{*}{$\begin{array}{l}\text { Position of base } \\
\text { or base pair }\end{array}$} & \multicolumn{6}{|c|}{ Base or base pair in species or group: } \\
\hline & $\begin{array}{c}\text { M. hominis } \\
\text { cluster }\end{array}$ & $\begin{array}{c}\text { M. gypis } \\
\text { B1/T1 }^{\mathrm{T}}\end{array}$ & $\begin{array}{c}\text { 'Candidatus } \\
\text { M. ravipulmonis' }\end{array}$ & $\begin{array}{l}\text { Hominis } \\
\text { group }\end{array}$ & Mollicutes & Exceptions \\
\hline $126 \cdot 235$ & $\mathrm{G} \cdot \mathrm{U}^{*}$ & $\mathrm{G} \cdot \mathrm{U}$ & $\mathrm{A} \cdot \mathrm{U}$ & $\mathrm{A} \cdot \mathrm{U}$ & $\mathrm{A} \cdot \mathrm{U}$ & $\mathrm{A} \cdot \mathrm{U}:$ M. canadense, M. spumans \\
\hline $131 \cdot 231$ & $\mathrm{U} \cdot \mathrm{A}$ & $\mathrm{U} \cdot \mathrm{A}$ & $\mathrm{U} \cdot \mathrm{A}$ & $\mathrm{C} \cdot \mathrm{G}$ & $\mathrm{C} \cdot \mathrm{G}, \mathrm{U} \cdot \mathrm{A}$ & \\
\hline 152 & $\mathbf{C}^{*}$ & A & A & $\mathrm{A}, \mathrm{G}$ & A & A: M. arthritidis, U: M. subdolum \\
\hline $316 \cdot 337$ & $\mathrm{U} \cdot \mathrm{A}$ & $\mathrm{C} \cdot \mathrm{G}$ & $\mathrm{C} \cdot \mathrm{G}$ & $\mathrm{C} \cdot \mathrm{G}$ & $\mathrm{A} \cdot \mathrm{U}, \mathrm{U} \cdot \mathrm{R}$ & \\
\hline $409 \cdot 433$ & $\mathrm{C} \cdot \mathrm{G}^{*}$ & $\mathrm{C} \cdot \mathrm{G}$ & $\mathrm{G} \cdot \mathrm{C}$ & $\mathrm{G} \cdot \mathrm{C}$ & $\mathrm{C} \cdot \mathrm{G}, \mathrm{U} \cdot \mathrm{A}$ & $\mathrm{U} \cdot \mathrm{G}:$ M. auris, M. buccale \\
\hline 479 & $\mathrm{C}^{*}$ & $\mathrm{C}$ & $\mathrm{G}$ & $\mathrm{A}, \mathrm{U}$ & $\mathrm{c}, \mathrm{g}, \mathrm{U}$ & $\mathrm{U}:$ M. salivarium \\
\hline $504 \cdot 541$ & $\mathbf{U} \cdot \mathrm{G}$ & $\mathbf{U} \cdot \mathrm{G}$ & $\mathbf{U} \cdot \mathrm{G}$ & $\mathrm{C} \cdot \mathrm{G}^{\dagger}$ & $\mathrm{C} \cdot \mathrm{G}$ & $\begin{array}{l}\mathrm{U} \cdot \mathrm{G}: M . \text { neurolyticum cluster } \\
\text { (four species) }\end{array}$ \\
\hline $586 \cdot 755$ & $\mathrm{C} \cdot \mathrm{G}^{*}$ & $\mathrm{U} \cdot \mathrm{A}$ & $\mathrm{U} \cdot \mathrm{A}$ & $\mathrm{U} \cdot \mathrm{A} \dagger$ & $\mathrm{C} \cdot \mathrm{G}, \mathrm{u} \cdot \mathrm{a}$ & $\begin{array}{l}\mathrm{U} \cdot \mathrm{A}: \text { M. anseris } ; \mathrm{C} \cdot \mathrm{G}: M . \\
\text { mobile, } \text { M. sualvi }\end{array}$ \\
\hline $613 \cdot 627$ & $\mathrm{C} \cdot \mathrm{G}$ & $\mathrm{U} \cdot \mathrm{G}$ & $\mathrm{C} \cdot \mathrm{G}$ & $\mathrm{U} \cdot \mathrm{A}, \mathrm{U} \cdot \mathrm{G}^{\dagger}$ & $\mathrm{C} \cdot \mathrm{G}, \mathrm{u} \cdot \mathrm{g}, \mathrm{a} \cdot \mathrm{u}$ & $\begin{array}{l}\mathrm{U} \cdot \mathrm{G}: \text { M. cloacale; } \mathrm{C} \cdot \mathrm{G}: \text { ' } M . \\
\text { agassizii', M. pulmonis }\end{array}$ \\
\hline $660 \cdot 745$ & $\mathrm{G} \cdot \mathrm{C}^{*}$ & $\mathrm{G} \cdot \mathrm{C}$ & $\mathrm{U} \cdot \mathrm{A}$ & $\mathrm{U} \cdot \mathrm{A}, \mathrm{c} \cdot \mathrm{g}$ & $\mathrm{A} \cdot \mathrm{U}, \mathrm{G} \cdot \mathrm{C}$ & $\mathrm{G} \cdot \mathrm{U}:$ M. salivarium, $M$. subdolum \\
\hline $681 \cdot 709$ & $\mathrm{~A} \cdot \mathrm{U}$ & $\mathrm{A} \cdot \mathrm{U}$ & $\mathrm{A} \cdot \mathrm{U}$ & $\mathrm{U} \cdot \mathrm{A} \dagger$ & & $\begin{array}{l}\mathrm{A} \cdot \mathrm{U}: \text { ' } M . \text { agassizii', M. lipohilum, } \\
\text { M. mobile }\end{array}$ \\
\hline $831 \cdot 855$ & $\mathrm{C} \cdot \mathrm{G}$ & $\mathrm{C} \cdot \mathrm{G}$ & $\mathrm{U} \cdot \mathrm{G}$ & $\mathrm{U} \cdot \mathrm{G}, \mathrm{u} \cdot \mathrm{a} \dagger$ & $\mathrm{U} \cdot \mathrm{G}, \mathrm{c} \cdot \mathrm{g}$ & $\mathrm{C} \cdot \mathrm{G}:$ M. sualvi \\
\hline $961 \cdot 974$ & $\mathrm{U} \cdot \mathbf{G}$ & $\mathrm{U} \cdot \mathbf{G}$ & $\mathrm{U} \cdot \mathbf{G}$ & $\mathrm{U} \cdot \mathrm{U}$ & $\mathrm{U} \cdot \mathrm{A}, \mathrm{U} \cdot \mathrm{U}$ & \\
\hline 1091 & $\mathbf{C}^{*}$ & $\mathrm{U}$ & $\mathrm{U}$ & $\mathrm{U}$ & $\mathrm{U}$ & $\mathrm{U}:$ M. falconis \\
\hline 1320 & $\mathrm{U}^{*}$ & $\mathrm{C}$ & $\mathrm{C}$ & $\mathrm{C}$ & $\mathrm{C}, \mathrm{U}$ & C: M. subdolum \\
\hline
\end{tabular}

* Exceptions listed are those found among the members of the M. hominis cluster.

$\dagger$ Exceptions listed are members belonging to other clusters of the hominis group sharing the actual residue.

corresponding to $E$. coli. This truncation results in the counterpart residue of the stem, a uridine, being unlikely to be a paired base, but constituting a unilaterally bulged residue in the matured $16 \mathrm{~S}$ rRNA molecule of the members of this cluster. This attribute was also shared by $M$. gypis $\mathrm{B} 1 / \mathrm{T} 1^{\mathrm{T}}$, but not by 'Candidatus M. ravipulmonis'. Another structural motif was found in the locale of position 722 and 723, where most of the other members of the hominis group, i.e. the $M$. lipophilum cluster and the $M$. synoviae cluster, have an insertion of two nucleotides (Pettersson et al., 1996b). The M. neurolyticum cluster of the hominis group was previously characterized by having a one-nucleotide insertion in this position (Weisburg et al., 1989). The members of the M. hominis cluster, like most of the Bacteria and Archaea, lacked the inserted nucleotides in this locale of the 16S rRNA molecule. This insertion was also found to be absent in both $M$. gypis $\mathrm{B} 1 / \mathrm{T}^{\mathrm{T}}$ and 'Candidatus $\mathrm{M}$. ravipulmonis'. Similarly, the lines defined by the species ' $M$. agassizii' strain PS6 and $M$. pulmonis strain $\mathrm{PG} 34^{\mathrm{T}}$, and $M$. mobile strain $163 \mathrm{~K}^{\mathrm{T}}$ and $M$. sualvi strain Mayfield $\mathrm{B}^{\mathrm{T}}$, also lacked this attribute. However, the base composition in the actual region of these lineages was found to be slightly different as compared to that of the $M$. hominis cluster. Another higher order structural attribute was found in the $16 \mathrm{~S}$ rRNA molecule of the $M$. hominis group in the helix including the loop starting at position 1135. As judged from secondary structure models performed by comparative analysis of primary structures, this loop in the mollicutes is generally comprised of six nucleotides with a $2 \mathrm{bp}$ stem. Exceptions are found for the members of the $M$. synoviae cluster and the pneumoniae group, where this region is truncated by $\geqslant 10 \mathrm{nt}$ (Weisburg et al., 1989; Pettersson et al., 1996). The hexa-loop is closed by three base pairs in the $16 \mathrm{~S}$ rRNA molecule of the $M$. hominis cluster except for the type species of this cluster, M. hominis PG $21^{\mathrm{T}}$, which only showed two base pairs. The additional base pair constitutes the middle pair of the stem of the actual helix. It is positioned at $1133 \cdot 1141$ having the composition $\mathrm{R} \cdot \mathrm{Y}$. This base pair can also be found in other bacterial taxa, but was only found in some of the members of the phytoplasma cluster (formerly mycoplasma like organisms) among the mollicutes. Interestingly, both $M$. gypis $\mathrm{B} 1 / \mathrm{T}^{\mathrm{T}}$ and 'Candidatus M. ravipulmonis' were also found to have three base pairs in this region of the molecule indicating a close relationship to the $M$. hominis cluster. 


\section{Phylogeny versus biochemical properties of the M. hominis cluster}

The number of biochemical reactions suitable for phenotypic characterization of mollicutes is small. The fermentation of glucose and hydrolysis of arginine are the most widely used properties for this purpose. Interestingly, the members of the $M$. hominis cluster show a congruent biochemical pattern in that all are arginine hydrolysers without the ability to ferment glucose (Table 1). This type of stringent pattern (i.e. all members within a cluster having identical arginine and glucose utilization profiles) has not been found in any of the other clusters of the hominis group. This observation strongly supports the conclusion that members of the $M$. hominis cluster are closely related as revealed by the phylogenetic analysis above. Furthermore, $M$. gypis $\mathrm{B} 1 / \mathrm{T}^{\mathrm{T}}$ shares these phenotypic characteristics (Table 1), while the biochemical activities of the uncultured 'Candidatus M. ravipulmonis' remain to be established.

\section{Can 165 rDNA sequence similarity values be used for definition of species within the M. hominis cluster?}

The definition of a species varies within different groups of bacteria, and the limits under which a bacterial species can be defined is under constant debate. Phenotypic data should, whenever available, be considered for proposing new bacterial species (reviewed by Busse et al., 1996; Vandamme et al., 1996; and Wayne et al., 1987). However, biochemical and enzymic profiles seldom constitute adequate descriptive data for the delineation of species for bacterial systematics regarding fastidious micro-organisms such as the mollicutes. The current criteria for describing new mollicutes rests very strongly upon serological distinctions. The putative new species should be subjected to a variety of recommended serological techniques against antisera from all described species, at least within species of the putative genus (International Committee on Systematic Bacteriology Subcommittee on the taxonomy of Mollicutes, 1995). This is not only a cumbersome method, but its use is also limited to just a few laboratories where extensive efforts have been made to prepare the requisite antisera. Moreover, serologic cross-reactions which have been observed may contribute to the difficulty in differentiating new species. Evolutionarily, serological analyses cannot generally reveal a detailed picture about ancestral genotypes of new species, making the more recently described molecular methods necessary for this type of information. The need for phylogenetic analysis of taxa, for which classical tests in taxonomy have low discriminatory power, is obvious and general guidelines for species designation on a molecular level have been proposed (Stackebrandt \& Goebel, 1994). The recommendations relied on the statement that a $70 \%$ DNA-DNA reassociation value is the upper limit for designation of species (Wayne et al., 1987), and the fact that this limit was not exceeded between species showing a $16 \mathrm{~S}$ rRNA sequence similarity value $\leqslant 97 \%$. From these findings Stackebrandt \& Goebel (1994) concluded that when two species show a 16S rRNA sequence similarity above $97 \%$, DNA-DNA reassociation experiments should be carried out to investigate whether the species status should be regarded as relevant. The use of $16 \mathrm{~S}$ rDNA similarity values as an aid for classification of new species of the mycoplasmas was discussed recently by Heldtander et al. (1998). The proposed procedure would require only a minor set of antisera, provided that a complete collection of 16S rRNA gene sequences from all type strains exists. Therefore, one of the aims of this study was to correlate the limits of $16 \mathrm{~S}$ rRNA variability to the species rank within the $M$. hominis cluster. The phylogenetic analysis of the members of the $M$. hominis cluster indicates that most species are closely related according to the tree in Fig. 1 and sequence distance calculations. About half of the members of the $M$. hominis cluster showed rather uniform 16S rRNA gene sequence similarity percentage values, typically ranging from 94.2 to $97.2 \%$. These similarity values are within or very close to the limits for the justification of species as discussed above. $M$. indiense $3 \mathrm{~T}^{\mathrm{T}}$ and $M$. orale $\mathrm{CH} 19299^{\mathrm{T}}$ on one hand, and $M$. cloacale $383^{\mathrm{T}}$ and M. anseris $1219^{\mathrm{T}}$ on the other hand, were found to be $99.2 \%$ and $98.2 \%$ similar, respectively, which would also suggest that DNA-DNA reassociation studies should be pursued to clearly establish their status as separate species. The entity comprising five phylogenetically closely related species, forming the $M$. alkalescens subcluster, showed high 16S rDNA similarity values in the range of $98 \cdot 1 \%$ to $99 \cdot 4 \%$. Again, examination of their DNA-DNA relatedness would be useful to establish whether they all constitute individual species or if a subspecies-based nomenclature would be more appropriate. On the other hand, it might turn out that some or even all of them should remain being classified as separate species (i.e. $<70 \%$ DNA similarity), despite a $16 \mathrm{~S}$ rDNA similarity above 98 \% (Fox et al., 1992; Stackebrandt \& Goebel, 1994). For example Mycoplasma agalactiae and Mycoplasma bovis were shown to be $99.8 \%$ similar (Mattsson et al., 1994; Pettersson et al., 1996), but they have nevertheless been classified as separate species by DNADNA hybridization experiments and serology (Askaa \& Ernø, 1976). There are other examples of mycoplasmas with very high $16 \mathrm{~S}$ rDNA similarity values, such as Mycoplasma gallisepticum and Mycoplasma imitans, 99.9\% (Boyle \& Morrow, 1994), Mycoplasma cottewii and Mycoplasma yeatsii, $99 \cdot 7 \%$ (Heldtander et al., 1998) and between the species and subspecies within the M. mycoides cluster (Pettersson et al., 1996a). Although DNA-DNA reassociation data are only available for some of these species (Christansen \& Ernø, 1982; Bonnet et al., 1993), the serological data support their classification into different species or subspecies (Bradbury et al., 1993; Leach et al., 1993; DaMassa et al., 1994). When the 16S rRNA sequence similarity value is high (above say $99 \%$ ) for mycoplasma strains representing two species, it is important to analyse several strains of the species to judge the 
usefulness of $16 \mathrm{~S}$ rRNA sequence data for discrimination of species.

We believe the genetic variation in the 16S rRNA genes of species in the $M$. hominis cluster reported here is a valuable guide in describing new species in the class Mollicutes. This conclusion is based on the fact that our 16S rRNA gene sequence data support most, and perhaps all, mycoplasmas positioned in the $M$. hominis cluster, as well as supporting their taxonomic status as individual species proposed earlier on serological analyses. Consequently, if a $16 \mathrm{~S}$ rDNA sequence indicates that the isolate should be included in this taxonomic cluster of the mollicutes, the serological testing can, in principle, be restricted to reciprocal tests directed just to those members of the immediate phylogenetic neighbourhood (i.e. clusters or subclusters) of the putative new species. However, we suggest that the final decision in this recommendation should be made by a consensus of the International Committee on Systematic Bacteriology Subcommittee on the taxonomy of Mollicutes. Recently, a similar procedure was proposed and discussed in order to elucidate taxonomic groups within the plant-pathogenic phytoplasmas, and to designate Candidatus Phytoplasma species names for temporary use until these agents might be cultivated in artificial media (Lee et al., 1998).

\section{Concluding remarks}

The evolutionary relationships among the species we have assigned here to the $M$. hominis cluster have been based on the reported 16S rRNA gene sequences. A detailed phylogenetic picture of the $M$. hominis cluster was obtained by analysing these sequences and the cluster currently comprises 19 species sharing a $16 \mathrm{~S}$ rDNA sequence similarity of $\geqslant 94 \%$ (Table 1, Fig. 1). The $M$. hominis cluster was found to be phylogenetically stable as judged from confidence tests using bootstrap analysis, the presence of signature nucleotides, and observed higher-order structural elements in the 16S rRNA molecule. We have also suggested guidelines for the use of sequence analysis of the $16 \mathrm{~S}$ rRNA genes in classification of new species belonging to the M. hominis cluster. We recommend $16 \mathrm{~S}$ rDNA sequence analysis to be used for characterization of a putatively new species and if it is found to group with the members of the $M$. hominis cluster, it should be sufficient to test that strain in serological analysis only against antisera of the members of this cluster. It may even eventually prove feasible to restrict the serologic analysis to members of a subcluster only, but we believe that more sequence data from many different strains of the species within the $M$. hominis cluster will have to be available before such a decision can be taken. Finally, we suggest that sequence analysis of the $16 \mathrm{~S}$ rRNA gene(s) should be a strong recommendation for defining a new species within the mollicutes, as has been noted by the currently accepted 'Minimum standards for description of new species of the class Mollicutes (division Tenericutes)' (International Com- mittee on Systematic Bacteriology Subcommittee on the taxonomy of Mollicutes, 1995).

\section{ACKNOWLEDGEMENTS}

We thank Marianne Persson, Frost Stefan Jernstedt and Virginia Melys for valuable technical assistance. We also thank Dr Tomas Hultman at Amersham Pharmacia Biotech AB, Uppsala, Sweden, for providing gel solutions for DNA sequencing. This work has been financially supported by grants from the Swedish Foundation for Strategic Research to B.P. and the Research Foundation of SVA (National Veterinary Institute) to K.-E.J. The project forms a part of the EU research collaboration project COST 826 on 'Ruminant's Mycoplasmoses'.

\section{REFERENCES}

Allam, N. M. \& Lemcke, R. M. (1975). Mycoplasmas isolated from the respiratory tract of horses. J Hyg Camb 74, 385-407.

Askaa, G. \& Ernø, H. (1976). Elevation of Mycoplasma agalactiae subsp. bovis to species rank: Mycoplasma bovis (Hale et al.) comb. nov. Int J Syst Bacteriol 26, 323-325.

Blank, W. A., Erickson, B. Z. \& Stemke, G. (1996). Phylogenetic relationships of the porcine mycoplasmas Mycoplasma hyosynoviae and Mycoplasma hyopharyngis. Int J Syst Bacteriol 46, 1181-1182.

Bölske, G. (1988). Survey of mycoplasma infections in cell cultures and a comparison of detection methods. Zentbl Bakteriol Hyg A269, 331-340.

Bonnet, F., Saillard, C., Bové, J. M., Leach, R. H., Rose, D. L., Cottew, G. S. \& Tully, J. G. (1993). DNA relatedness between field isolates of mycoplasma F38 group, the agent of contagious caprine pleuropneumonia, and strains of Mycoplasma capricolum. Int J Syst Bacteriol 43, 597-602.

Boyle, J. S. \& Morrow, C. J. (1994). Phylogeny of avian mycoplasmas: Implications for mollicute taxonomy. IOM Lett 3, 589-590.

Bradbury, J. M. \& Forrest, M. (1984). Mycoplasma cloacale, a new species isolated from a turkey. Int J Syst Bacteriol 34, 389-392.

Bradbury, J. M., Jordan, F. T. W., Shimizu, T., Stipkovits, L. \& Varga, Z. (1988). Mycoplasma anseris sp. nov. found in geese. Int J Syst Bacteriol 38, 74-76.

Bradbury, J. M., Saed Abdul-Wahab, O. M., Yavari, C. A., Dupiellet, J.-P. \& Bové, J. M. (1993). Mycoplasma imitans sp. nov. is related to Mycoplasma gallisepticum and found in birds. Int $J$ Syst Bacteriol 43, 721-728.

Brosius, J., Palmer, J. L., Kennedy, P. J. \& Noller, H. F. (1978). Complete nucleotide sequence of a $16 \mathrm{~S}$ ribosomal RNA gene from Escherichia coli. Proc Natl Acad Sci USA 75, 4801-4805.

Brown, D. R., McLaughlin, G. S. \& Brown, M. B. (1995). Taxonomy of the feline mycoplasmas Mycoplasma felifaucium, Mycoplasma feliminutum, Mycoplasma felis, Mycoplasma gateae, Mycoplasma leocaptivus, Mycoplasma leopharyngis, and Mycoplasma simbae by 16S rRNA gene sequence comparisons. Int J Syst Bacteriol 45, 560-564.

Busse, H.-J., Denner, E. B. M. \& Lubitz, W. (1996). Classification and identification of bacteria: current approaches to an old problem. Overview of methods used in bacterial systematics. J Biotechnol 47, 3-38.

Christansen, G. \& Ernø, H. (1982). Classification of the F38 group of caprine mycoplasma strains by DNA hybridization. J Gen Microbiol 128, 2523-2526. 
DaMassa, A. J., Tully, J. G., Rose, D. L., Pitcher, D., Leach, R. H. \& Cottew, G. S. (1994). Mycoplasma auris sp. nov. Mycoplasma cottewii sp. nov., and Mycoplasma yeatsii sp. nov., new sterolrequiring mollicutes from the external ear canals of goats. Int $J$ Syst Bacteriol 44, 479-484.

Edward, D. G. ff. \& Fitzgerald, W. A. (1951). The isolation of organisms of the pleuropneumonia group from dogs. J Gen Microbiol 5, 566-575.

Felsenstein, J. (1993). PHYLIP: phylogeny inference package (version 3.57). Department of Genetics, University of Washington, Seattle, WA, USA.

Fox, G. E., Wisotzkey, J. D. \& Jurtshuk, P., Jr (1992). How close is close: 16S rRNA sequence identity may not be sufficient to guarantee species identity. Int J Syst Bacteriol 42, 166-170.

Freundt, E. A., Taylor-Robinson, D., Purcell, R. H., Chanock, R. M. \& Black, F. T. (1974). Proposal of Mycoplasma buccale nom. nov. and Mycoplasma faucium nom. nov. for Mycoplasma orale 'types' 2 and 3, respectively. Int J Syst Bacteriol 24, 252-255.

Gray, M. W., Sankoff, D. \& Cedergren, R. J. (1984). On the evolutionary descent of organisms and organelles: a global phylogeny based on a highly conserved structural core in small subunit ribosomal RNA. Nucleic Acids Res 12, 5837-5852.

Heldtander, M., Pettersson, B., Tully, J. G. \& Johansson, K.-E. (1998). Sequences of the 16S rRNA genes and phylogeny of the goat mycoplasmas Mycoplasma adleri, Mycoplasma auris, Mycoplasma cottewii and Mycoplasma yeatsii. Int J Syst Bacteriol 48, 263-268.

Hill, A. C. (1993). Mycoplasma indiense sp. nov., isolated from the throats of nonhuman primates. Int $J$ Syst Bacteriol 43, 36-40.

Hultman, T., Ståhl, S., Hornes, E. \& Uhlén, M. (1989). Direct solid phase sequencing of genomic and plasmid DNA using magnetic beads as solid support. Nucleic Acids Res 17, 4937-4946.

Hultman, T., Bergh, S., Moks, T. \& Uhlén, M. (1991). Bidirectional solid phase sequencing of in vitro-amplified plasmid DNA. BioTechniques 10, 84-93.

International Committee on Systematic Bacteriology Subcommittee on the taxonomy of Mollicutes (1995). Revised minimum standards for description of new species of the class Mollicutes (division Tenericutes). Int J Syst Bacteriol 45, 605-612.

Johansson, K.-E., Heldtander, M. U. K. \& Pettersson, B. (1998). Characterization of mycoplasmas by PCR and sequence analysis with universal 16S rDNA primers. In Methods in Molecular Biology, Mycoplasma Protocols, vol. 104, pp. 145-165. Edited by R. J. Miles \& R. A. J. Nicholas. Totowa, NJ: Humana Press.

Jukes, T. H. \& Cantor, C. R. (1969). Evolution of protein molecules. In Mammalian Protein Metabolism, pp. 21-132. Edited by H. N. Munro. New York: Academic Press.

Leach, R. H., Ernø, H. \& MacOwan, K. J. (1993). Proposal for designation of F38-type caprine mycoplasmas as Mycoplasma capricolum subsp. capripneumoniae subsp. nov. and consequent obligatory relegation of strains currently classified as $M$. capricolum (Tully, Barile, Edward, Theodore, and Ernø 1974) to an additional new subspecies, $M$. capricolum subsp. capricolum subsp. nov. Int $J$ Syst Bacteriol 43, 603-605.

Lee, I.-M., Gundersen-Rindal, D. E., Davis, R. E. \& Bartoszyk, I. M. (1998). Revised classification scheme of phytoplasmas based on RFLP analyses of $16 \mathrm{~S}$ rRNA and ribosomal protein gene sequences. Int J Syst Bacteriol 48, 1153-1169.

Lemcke, R. M. \& Kirchhoff, J. (1979). Mycoplasma subdolum, a new species isolated from horses. Int J Syst Bacteriol 29, 42-50.
Maidak, B. L., Cole, J. R., Parker, C. T., Jr \& 11 other authors (1999). A new version of the RDP (Ribosomal Database Project). Nucleic Acids Res 27, 171-173.

Mattsson, J. G., Guss, B. \& Johansson, K.-E. (1994). The phylogeny of Mycoplasma bovis as determined by sequence analysis of the 16S rRNA gene. FEMS Microbiol Lett 115, 325-328.

Mygind, T., Birkelund, S. \& Christiansen, G. (1998). DNA sequencing reveals limited heterogeneity in the 16S rRNA gene from the $r r n B$ operon among five Mycoplasma hominis isolates. Int J Syst Bacteriol 48, 1067-1071.

Neimark, H., Mitchelmore, D. \& Leach, R. H. (1998). An approach to characterizing uncultivated prokaryotes: the grey lung agent and proposal of a Candidatus taxon for the organism, 'Candidatus Mycoplasma ravipulmonis'. Int J Syst Bacteriol 48, 389-394.

Olsen, G. J. \& Woese, C. R. (1993). Ribosomal RNA: a key to phylogeny. FASEB J 7, 113-123.

Pettersson, B., Johansson, K.-E. \& Uhlén, M. (1994). Sequence analysis of $16 \mathrm{~S}$ rRNA from mycoplasmas by direct solid-phase DNA sequencing. Appl Environ Microbiol 60, 2456-2461.

Pettersson, B., Leitner, T., Ronaghi, M., Bölske, G., Uhlén, M. \& Johansson, K.-E. (1996a). Phylogeny of the Mycoplasma mycoides cluster as determined by sequence analysis of the $16 \mathrm{~S}$ rRNA genes from the two rRNA operons. J Bacteriol 178, 4131-4142.

Pettersson, B., Uhlén, M. \& Johansson, K.-E. (1996b). Phylogeny of some mycoplasmas from ruminants based on $16 \mathrm{~S}$ rRNA sequences and definition of a new cluster within the hominis group. Int J Syst Bacteriol 46, 1093-1098.

Pettersson, B., Bölske, G., Thiaucourt, F., Uhlén, M. \& Johansson, K.-E. (1998). Molecular evolution of Mycoplasma capricolum subsp. capripneumoniae strains, based on polymorphisms in the 16S rRNA genes. J Bacteriol 180, 2350-2358.

Poveda, J. B., Giebel, J., Flossdorf, J., Meier, J. \& Kirchhoff, H. (1994). Mycoplasma buteonis sp. nov., Mycoplasma falconis sp. nov., and Mycoplasma gypis sp. nov., three species from birds of prey. Int J Syst Bacteriol 44, 94-98.

Rawadi, G., Dujeancourt-Henry, A., Lemercier, B. \& RoullandDussoix, D. (1998). Phylogenetic position of rare human mycoplasmas, Mycoplasma faucium, M. buccale, M. primatum and $M$. spermatophilum, based on $16 \mathrm{~S}$ rRNA gene sequences. Int $J$ Syst Bacteriol 48, 305-309.

Ribosomal Database Project (RDP-II) (1999). Release 7.0. Michigan State University, East Lansing, MI, USA.

Ross, R. F. (1993). Mycoplasma Animal Pathogens. In Rapid Diagnosis of Mycoplasmas, pp. 69-109. Edited by I. Kahane \& A. Adoni. New York: Plenum.

Saitou, N. \& Nei, M. (1987). The neighbor-joining method: a new method for reconstructing phylogenetic trees. Mol Biol Evol 4, 406-425.

Smith, S. (1992). GDE: Genetic data environment, version 2.2. Millipore Imaging systems, Ann Arbor, MI, USA.

Stackebrandt, E. \& Goebel, B. M. (1994). Taxonomic note: a place for DNA-DNA reassociation and 16S rRNA sequence analysis in the present species definition in bacteriology. Int $J$ Syst Bacteriol 44, 846-849.

Vandamme, P., Pot, B., Gillis, M., De Vos, P., Kersters, K. \& Swings, J. (1996). Polyphasic taxonomy, a consensus approach to bacterial systematics. Microbiol Rev 60, 407-438.

Van de Peer, Y., Chapelle, S. \& De Wachter, R. (1996). A 
quantitative map of nucleotide substitution rates in bacterial 16S rRNA. Nucleic Acids Res 24, 3381-3391.

Wayne, L. G., Brenner, D. J., Colwell, R. R. \& 9 other authors (1987). International Committee on Systematic Bacteriology. Report of the ad hoc committee on reconciliation of approaches to bacterial systematics. Int J Syst Bacteriol 37, 463-464.

Weisburg, W. G., Tully, J. G., Rose, D. L. \& 9 other authors (1989).
A phylogenetic analysis of the mycoplasmas: basis for their classification. J Bacteriol 171, 6455-6467.

Woese, C. R. (1987). Bacterial evolution. Microbiol Rev 51, 221-271.

Woese, C. R., Maniloff, J. \& Zablen, L. B. (1980). Phylogenetic analysis of the mycoplasmas. Proc Natl Acad Sci USA 77, 494-498. 